\title{
Controle de larvas de Boophilus microplus por Metarhizium anisopliae em pastagens infestadas artificialmente
}

\author{
Lúcia Mara de Souza Basso(1), Antonio Carlos Monteiro(1) ${ }^{(1)}$ arco Antonio de Andrade Belo ${ }^{(2)}$, \\ Vando Edesio Soares ${ }^{(2)}$, Marcos Valério Garcia ${ }^{(1)}$ e Dinalva Alves Mochi ${ }^{(1)}$
}

\begin{abstract}
(1)Universidade Estadual Paulista (Unesp), Fac. de Ciências Agrárias e Veterinárias (FCAV), Dep. de Produção Vegetal, Via de Acesso Prof. Paulo Donato Castellane, s/no, CEP 14884-900 Jaboticabal, SP. E-mail: montecar@fcav.unesp.br, marcos@fcav.unesp.br, dmochi@ig.com.br (2)Unesp, FCAV, Dep. de Patologia Veterinária.E-mail: maabelo@hotmail.com, vandos@hotmail.com
\end{abstract}

\begin{abstract}
Resumo - O objetivo deste trabalho foi avaliar a eficiência do controle exercido por Metarhizium anisopliae na população de Boophilus microplus, em pastagens de Brachiaria brizantha, e do híbrido Tifton 85 (Cynodon spp.), artificialmente infestadas com fêmeas ingurgitadas do carrapato. Trinta canteiros com $1 \mathrm{~m}^{2}$ de área cada foram distribuídos aleatoriamente. Quinze foram pulverizados com esporos do fungo e quinze controles em cada forrageira, constituindo cinco repetições de cada tratamento, foram infestados com número e peso padronizados de fêmeas ingurgitadas do ácaro. Aplicou-se o fungo, na concentração de $1,8 \times 10^{8}$ conídios $\mathrm{mL}^{-1}$, em três situações: pulverização antes da infestação com o carrapato, após a infestação e posterioriormente à emergência das

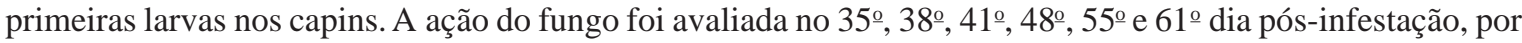
meio da contagem de larvas recuperadas. Obteve-se controle de larvas do ácaro, que, nas avaliações realizadas entre o $35^{\circ}$ e o $48^{\circ}$ dia pós-infestação, variou entre $87 \%$ e $94 \%$. As médias das contagens de estágios larvares do carrapato foram menores em todas as amostragens realizadas no capim-Tifton 85, indicando que houve efeito da pastagem na ação do fungo. A situação de aplicação influencia a atividade do fungo, com melhor resultado nas coletas realizadas entre o 41ํ e 55ํㅡㅁ dia após infestação em B. brizantha, e aplicação dos conídios logo após a emergência das primeiras larvas.
\end{abstract}

Termos para indexação: Brachiaria brizantha, Tifton 85, carrapato, controle biológico, fungo entomopatogênico.

\section{Control of Boophilus microplus larvae by Metarhizium anisopliae in artificially infested pastures}

\begin{abstract}
The objective of this work was to evaluate the efficiency of Metarhizium anisopliae fungus against Boophilus microplus population in Brachiaria brizantha and Tifton 85 (Cynodon) pastures, artificially infested with tick engorged females. Thirty plots of $1 \mathrm{~m}^{2}$ each were randomly distributed in fifteen treated and fifteen control groups per type of grass, establishing five repetitions for each treatment. Pastures were infested with engorged tick females standardized by number and weight. Metarhizium anisopliae suspension with $1.8 \times 10^{8}$ conidia $\mathrm{mL}^{-1}$ concentration was sprayed on the plot in three different assays, prior infested with tick females, immediately after tick inoculation and at first larvae emergency. The fungus action was evaluated at $35^{\text {th }}$, $38^{\text {th }}, 41^{\text {st }}, 48^{\text {th }}, 55^{\text {th }}$ and $61^{\text {st }}$ day post infestation by counting recovered larvae. A significative reduction of larvae counts occurred in fungus treated groups during $35^{\text {th }}$ to $48^{\text {th }}$ day post infestation, ranging between $87 \%$ and $94 \%$ of efficacy on tick larvae control. The mean values for larvae counting in Tifton 85 pasture were lower than in B. brizantha plot in all analysis, suggesting the pasture effect on fungus action. Treatment strategy influenced on M. anisopliae activity, which demonstrated better results at $41^{\text {st }}$ and $55^{\text {th }}$ day post infestation in $B$. brizantha, submitted to conidia challenge after larvae emergency.
\end{abstract}

Index terms: Brachiaria brizantha, Tifton 85, tick, biological control, entomopathogenic fungus.

\section{Introdução}

O carrapato dos bovinos, Boophilus microplus, é um ectoparasita que gera prejuízos para pecuária de corte e leite. Perdas diretas e indiretas relacionadas a esta parasitose foram estimadas em 8 dólares bovino ${ }^{-1}$ ano $^{-1}$. Os prejuízos podem ultrapassar um bilhão de dólares anuais no Brasil, levando-se em conta a diminuição na produção de leite, aumento da mortalidade, redução da natalidade, consumo de carrapaticidas, perdas de peso, gastos com mão-de-obra, perda na qualidade do couro além da transmissão de agentes patogênicos (Embrapa, 2004).

Programas de controle do B. microplus buscam interromper seu ciclo de vida na fase parasitária, empregando compostos químicos sintéticos com atividade acaricida. Entretanto, o uso inadequado desses produ- 
tos pode resultar na diminuição da eficiência da droga e, conseqüentemente, na redução da eficácia dos tratamentos (Cordovés, 1997). A identificação de competitividade entre organismos em um ecossistema específico representa perspectiva promissora para o tratamento de inúmeras enfermidades, em substituição ao uso de compostos químicos. Neste contexto, o controle biológico de carrapatos utilizando agentes microbianos, especialmente fungos, tem apresentado resultados potencialmente satisfatórios, apesar de sua aplicabilidade estar restrita a testes in vitro e diretamente no hospedeiro. Pouco se sabe da atividade patogênica de fungos em teleóginas presentes nas pastagens (Bittencourt, 1994).

Trabalhos envolvendo o emprego de fungos no controle biológico de carrapatos são crescentes. Estudos in vitro mostraram que $M$. anisopliae tem ação patogênica sobre B. microplus (Monteiro et al., 1998; Frazzon et al., 2000). A patogenicidade ao carrapato em animais estabulados foi investigada por Castro et al. (1997) e Correia et al. (1998), ao passo que Castro et al. (1999) e Bittencourt et al. (2003) avaliaram a ação do fungo, aplicado em Brachiaria decumbens, no controle de larvas do carrapato. No entanto, há poucas pesquisas que busquem determinar a patogenicidade do fungo sobre o carrapato em condições de campo e, como conseqüência, não existe recomendação de uso deste patógeno em programas de controle integrado do ácaro (Bittencourt, 1994).

O crescimento populacional de $M$. anisopliae no ambiente depende, entre outros fatores, das condições climáticas e do tipo de forrageira que constitui a pastagem (Gauss \& Furlong, 2002). Tais fatores podem intervir significativamente no sucesso do controle biológico. Forrageiras que apresentam a formação de estolões, como os capins do gênero Cynodon, podem favorecer o desenvolvimento do fungo no solo com a retenção de umidade, enquanto forrageiras cespitosas, como as plantas do gênero Brachiaria, formam touceiras que não são tão eficientes na retenção de umidade (Saueressig, 1994), criando um microclima mais favorável para o ciclo de vida não parasitário do carrapato.

A proposta deste trabalho é avaliar a eficiência do controle exercido por M. anisopliae na população de B. microplus em pastagens de Brachiaria brizantha e do híbrido Tifton 85 (Cynodon spp.), artificialmente infestadas com fêmeas ingurgitadas do carrapato.

\section{Material e Métodos}

O trabalho foi realizado de fevereiro a maio de 2003, em área de pastagens pertencente à coleção do Setor de Forragicultura do Dep. de Zootecnia da FCAV, Unesp, Campus de Jaboticabal, SP, situado a $21^{\circ} 14^{\prime} 5^{\prime \prime} \mathrm{S}$ e 48¹7'9" W e altitude média de 613,68 m. O clima da região, segundo a classificação de Köppen, é Cwa, isto é, subtropical úmido, seco no inverno e com chuvas no verão. A precipitação média anual fica em torno de $1.424 \mathrm{~mm}$ e a temperatura média anual próxima de $21,5^{\circ} \mathrm{C}$. No período experimental, a amplitude de variação mensal da temperatura, da precipitação pluvial e da umidade relativa do ar registrada ficou, respectivamente, entre $19^{\circ} \mathrm{C}$ e $25,4^{\circ} \mathrm{C}, 86,7$ e $153,5 \mathrm{~mm}$, e $70,7 \%$ e $75,5 \%$.

Os carrapatos foram coletados em área com animais de alta infestação natural por B. microplus. As fêmeas ingurgitadas foram selecionadas, lavadas com água desionizada, pesadas e separadas em grupos de 15 , permanecendo por um dia em estufa sob temperatura de $28 \pm 0,5^{\circ} \mathrm{C}$.

Utilizou-se o fungo Metarhizium anisopliae, isolado E9, mantido em cultura estoque na coleção do Laboratório de Microbiologia do Dep. de Produção Vegetal da FCAV. O fungo foi cultivado em placas de Petri contendo meio BDA, acondicionadas em estufa a $27 \pm 0,5^{\circ} \mathrm{C}$, e um fotoperíodo de 12 horas. Em seguida, foi inoculado em fêmeas ingurgitadas de $B$. microplus e reisolado em placas com BDA, até se obter uma mortalidade de fêmeas superior a 90\%. Culturas do fungo com virulência recuperada foram levadas à empresa Biocontrol Sistema de Controle Biológico localizada no Município de Sertãozinho, SP, onde foi produzido em massa, segundo método descrito por Alves \& Pereira (1998). Em seguida, foi levado ao laboratório em sacos de plástico contendo $1 \mathrm{~kg}$ de arroz com fungo desenvolvido e congelado $\left(-20^{\circ} \mathrm{C}\right)$.

Sob condições assépticas, o arroz foi colocado em saco de plástico transparente, adicionando-se solução aquosa de Tween 80 a 0,1\% (v/v) e, então, foi agitado manualmente para desagregação dos grãos e liberação dos conídios. Em seguida, foi coado em pano de algodão fino, a fim de evitar o entupimento do bico do pulverizador no momento da aplicação, obtendo-se, assim, a calda, cuja concentração, determinada em microscópio ótico com auxílio da câmara de Neubauer, foi padronizada em $1,8 \times 10^{8}$ conídios $\mathrm{mL}^{-1}$. 
Como plantas forrageiras usaram-se Brachiaria brizantha e o híbrido Tifton 85 (Cynodon spp.). Em cada pasto foram preparados 30 canteiros, divididos em cinco blocos (repetições), formados por seis canteiros com $1 \mathrm{~m}^{2}$ quadrado de área cada um, disposto em três pares dentro do bloco. Em cada bloco foram sorteados, ao acaso, três canteiros para receberem o fungo, cada um correspondendo a uma das situações de pulverização abaixo descrita, e três canteiros para servirem como testemunha, respectivamente, de cada uma das situações de pulverização. Os canteiros ficaram lateralmente separados por 6,5 m e frontalmente por $10 \mathrm{~m}$. Cada canteiro teve identificação, manutenção de altura da planta em $25 \mathrm{~cm}$ e, em sua volta, manteve-se uma borda limpa de 1,5 m.

As pulverizações foram feitas em três situações: a) canteiros pulverizados com $200 \mathrm{~mL}$ de calda com concentração de $1,8 \times 10^{8}$ conídios $\mathrm{mL}^{-1}$, usando pulverizador manual com capacidade para $5 \mathrm{~L}$, com bico tipo cone e, em seguida, foram colocadas aleatoriamente, dentro de cada canteiro, 15 fêmeas ingurgitadas de B. microplus; b) canteiros infestados com 15 fêmeas ingurgitadas de $B$. microplus e, em seguida, pulverizados com a mesma calda, como anteriormente; c) canteiros infestados com fêmeas ingurgitadas de B. microplus, aplicando-se a calda com o fungo após a emergência das primeiras larvas. O volume de $200 \mathrm{~mL}$ de calda, necessário para molhar completamente o capim de cada canteiro, foi determinado em pré-ensaio.

Foram retirados os ápices das plantas em que as larvas vivas se acumularam, aos 35, 38, 41, 48, 55 e 61 dias pós-infestação. Em cada coleta, o material obtido em um mesmo canteiro foi acondicionado em um único saco de plástico, lacrado, identificado e congelado para posterior contagem das larvas. As larvas acumuladas em cada um dos ápices colhidos foram removidas com o auxílio de um pincel e colocadas em placa de Petri com gotas de glicerina em quantidade suficiente para desagregá-las; em seguida foram cuidadosamente separadas e contadas uma a uma, com ajuda de pinça e estilete.

Na verificação da ausência de larvas remanescentes nos canteiros após a última coleta, fizeram-se observações diárias por duas semanas, sem encontrar larvas. Em seguida, todas as plantas dos canteiros foram integralmente retiradas, colocadas em sacos de plástico identificados, lacrados e acondicionados em câmara fria a $4,5 \pm 0,5^{\circ} \mathrm{C}$ por um dia. Em mesa grande forrada com um pano branco, examinou-se folha por folha para certificação da ausência de larvas.

Os dados foram analisados em um esquema fatorial 2x2x3, em blocos inteiramente casualizados, sendo os fatores constituídos por duas espécies de capins, ausência ou presença do fungo e três sistemas de pulverizações. Os resultados foram submetidos à análise de variância pelo teste $\mathrm{F}$ e as médias dos tratamentos comparadas pelo teste de Tukey $(\mathrm{p}<0,05)$. O porcentual de controle foi calculado de acordo com fórmula proposta por Abbott (1925).

\section{Resultados e Discussão}

No estudo comparativo para determinação da atividade patogênica do fungo em condições de campo, verificou-se redução significativa $(\mathrm{P}<0,05)$ na quantidade de larvas recuperadas nos canteiros tratados, quando comparados aos canteiros testemunha do $35^{\circ}$ ao $48^{\circ}$ dia de análise (Tabela 1). Nesta análise não se consideraram as diferentes situações de pulverização do fungo e os tipos de pastagens. Nas contagens realizadas no $55^{\circ}$ e $61^{\circ}$ dia pós-infestação, não ocorreram diferenças $(\mathrm{P}>0,05)$ entre os grupos tratados com o fungo e as testemunhas. Isso provavelmente ocorreu em virtude da redução acentuada de larvas recuperadas nas testemunhas, como seria de se esperar cerca de 60 dias após a infestação, já que as pastagens não foram reinfestadas.

Houve uma redução de $87 \%$ a $94 \%$ na população de larvas (Tabela 1). O resultado deste trabalho concorda com o de Bittencourt et al. (1992) que, em estudo realizado in vitro, envolvendo a atividade patogênica do $M$. anisopliae sobre diferentes estágios do ciclo de vida do B. microplus, observaram acentuada redução na população de larvas após tratamento do ácaro com o fungo.

Tabela 1. Médias de larvas encontradas nas pastagens de Brachiaria brizantha e Tifton 85 infestadas com fêmeas ingurgitadas de Boophilus microplus e aplicação de Metarhizium anisopliae ${ }^{(1)}$.

\begin{tabular}{cccc}
\hline Dias pós-infestação & \multicolumn{2}{c}{ Tratamento } & Controle $(\%)^{(2)}$ \\
\cline { 2 - 3 } & M. anisopliae & Testemunha & \\
\hline 35 & $125,27 \pm 131,72 \mathrm{~b}$ & $1448,68 \pm 1402,22 \mathrm{a}$ & 91,35 \\
38 & $116,20 \pm 180,07 \mathrm{~b}$ & $892,87 \pm 646,56 \mathrm{a}$ & 86,99 \\
41 & $41,77 \pm 72,76 \mathrm{~b}$ & $377,33 \pm 638,08 \mathrm{a}$ & 88,93 \\
48 & $14,17 \pm 71,79 \mathrm{~b}$ & $239,47 \pm 446,50 \mathrm{a}$ & 94,08 \\
55 & $4,83 \pm 26,47 \mathrm{a}$ & $17,97 \pm 50,77 \mathrm{a}$ & 73,10 \\
61 & $1,23 \pm 4,70 \mathrm{a}$ & $6,80 \pm 25,89 \mathrm{a}$ & 81,86 \\
\hline
\end{tabular}

(1)Médias seguidas de mesma letra, na linha, não diferem entre si pelo teste deTukey $(\mathrm{P}>0,05)$; médias acompanhadas pelos respectivos erros-padrões. ${ }^{(2)}$ Calculado segundo fórmula de Abbott (1925). 
Castro et al. (1999) aplicaram, em dois ensaios, suspensões variando entre $10^{10}$ e $10^{5}$ conídios $\mathrm{mL}^{-1}$ de $M$. anisopliae em canteiros de B. decumbens previamente infestados com larvas não alimentadas de $B$. microplus. O número de larvas recuperadas nos canteiros tratados com qualquer uma das suspensões não diferiu da testemunha. Os autores concluíram que uma única pulverização do fungo é insuficiente para eliminar larvas do carrapato de forma estatisticamente significativa, mas ressalvaram que biologicamente os números denotaram pequena vantagem dos grupos tratados em relação aos controles. Bittencourt et al. (2003) avaliaram a ação de $M$. anisopliae aplicado nas concentrações de $10^{9}$ e $10^{7}$ conídios $\mathrm{mL}^{-1}$, em três ensaios com $B$. decumbens infestada com larvas de B. microplus. O fungo apresentou efeito deletério sobre o carrapato, pois os porcentuais de redução do número de larvas foram de 17,89 e 17,42, respectivamente, nas concentrações de $10^{7}$ e $10^{9}$ conídios $\mathrm{mL}^{-1}$ no primeiro bioensaio; de 22,53 e 52,26 no segundo; e de 37,84 e 53,78 no terceiro bioensaio.

Houve diminuição significativa $(\mathrm{P}<0,05)$ na quantidade de larvas nos canteiros com inoculação de fungo em relação aos grupos testemunha em ambas as pastagens estudadas (Tabela 2). O valor médio para contagem de estágios larvares do carrapato foi superior em todas as amostragens realizadas no capim B. brizantha comparado ao Tifton 85.

Estes resultados podem estar relacionados às condições microclimáticas determinadas em cada forrageira, que podem ou não favorecer a biologia do fungo e intervir nas condições ideais de sobrevivência do carrapato, sugerindo que haja efeito da pastagem no controle. Pelo fato de formar estolões, com grande quantidade de folhas e, conseqüentemente, maior cobertura vegetal, o Tifton 85 pode propiciar um microclima local mais favorável ao fungo, o que resultou em menor recuperação de larvas neste capim.
O microclima do pasto pode influenciar também a biologia do carrapato. Veríssimo \& Machado (1995) afirmaram que umidades relativas abaixo de $80 \%$ atuam negativamente na sobrevivência larval na pastagem. Segundo Saueressig (1994), as condições de microclima determinadas pelas gramíneas foram responsáveis pela menor população de larvas de B. microplus encontrada em pastagem de Andropogon gayanus quando comparadas a $B$. decumbens. Como o Tifton 85 produz grande quantidade de massa vegetal, semelhante ao A. gayanus, é possível que, concomitante à ação do fungo, tenha ocorrido efeito do microclima da pastagem na população de larvas neste experimento.

A temperatura média entre o 35ํㅜ e o 61ํ dias pósinfestação das fêmeas ingurgitadas nas forragens variou de $18,1^{\circ} \mathrm{C}$ a $23,1^{\circ} \mathrm{C}$, e a umidade relativa do ar oscilou entre $68 \%$ e $80,2 \%$ no mesmo intervalo. Tais valores indicam que as condições ambientais deste ensaio foram favoráveis à biologia do carrapato. Portanto, a recuperação significativamente menor de larvas nos tratamentos com M. anisopliae pode ser atribuída ao fungo que eliminou fêmeas, reduziu a oviposição, ou a eclosão de larvas, ou ainda, eliminou as próprias larvas.

Estudos sobre o controle biológico de carrapatos do gênero Boophilus spp. com M. anisopliae demonstraram excelente atividade patogênica em condições ambientais com temperaturas entre $25^{\circ} \mathrm{C}$ e $28^{\circ} \mathrm{C}$ e umidade relativa entre $60 \%$ e $70 \%$ (Kaaya \& Hassan, 2000), ou temperatura média de $28^{\circ} \mathrm{C}$ e umidade relativa em torno de 85\% (Frazzon et al., 2000). Os resultados obtidos e os encontrados pelos referidos autores indicam que o fungo é capaz de exercer a atividade patogênica sobre o carrapato em diferentes condições de temperatura e umidade. Quanto ao controle biológico, este é um importante fator a ser considerado, pois um bom agente de controle deverá atuar em diferentes condições ambientais.

As diferenças encontradas na recuperação de larvas entre as forrageiras (Tabela 3) sugerem que este efeito

Tabela 2. Ocorrência de larvas de Boophilus microplus nas pastagens de Brachiaria brizantha e Tifton 85 pulverizadas com Metarhizium anisopliae e infestadas com fêmeas ingurgitadas ${ }^{(1)}$.

\begin{tabular}{|c|c|c|c|c|c|c|c|}
\hline \multirow[t]{2}{*}{ Tratamento } & \multicolumn{7}{|c|}{ Dias pós-infestação } \\
\hline & 0 & 35 & 38 & 41 & 48 & 55 & 61 \\
\hline & & & & B. brizantha & & & \\
\hline M. anisopliae & $0,00 \pm 0,00$ & $214,67 \pm 109,73 b$ & $217,67 \pm 208,28 b$ & $83,53 \pm 85,03 b$ & $28,33 \pm 101,22 b c$ & $9,67 \pm 37,44 \mathrm{ab}$ & $2,47 \pm 6,51 \mathrm{a}$ \\
\hline Testemunha & $0,00 \pm 0,00$ & $1901,20 \pm 1829,41 \mathrm{a}$ & $918,20 \pm 691,72 \mathrm{a}$ & $754,67 \pm 746,67 \mathrm{a}$ & $375,73 \pm 551,88 \mathrm{a}$ & $35,93 \pm 69,35 \mathrm{a}$ & $13,60 \pm 36,53 \mathrm{a}$ \\
\hline Controle $(\%)^{(2)}$ & - & 88,71 & 76,29 & 88,93 & 92,46 & 73,10 & 81,86 \\
\hline $\begin{array}{l}\text { M. anisopliae } \\
\text { Testemunha }\end{array}$ & $\begin{array}{l}0,00 \pm 0,00 \\
0,00 \pm 0,00\end{array}$ & $\begin{array}{c}35,87 \pm 82,30 \mathrm{c} \\
1525,15 \pm 645,55 \mathrm{a}\end{array}$ & $\begin{array}{c}14,73 \pm 41,56 \mathrm{c} \\
1103,13 \pm 637,56 \mathrm{a}\end{array}$ & $\begin{array}{l}\text { Tifton } 85 \\
0,00 \pm 0,00 \mathrm{c} \\
0,00 \pm 0,00 \mathrm{c}\end{array}$ & $\begin{array}{c}0,00 \pm 0,00 \mathrm{c} \\
211,98 \pm 280,87 \mathrm{~b}\end{array}$ & $\begin{array}{l}0,00 \pm 0,00 \mathrm{~b} \\
0,00 \pm 0,00 \mathrm{~b}\end{array}$ & $\begin{array}{l}0,00 \pm 0,00 \mathrm{a} \\
0,00 \pm 0,00 \mathrm{a}\end{array}$ \\
\hline $\begin{array}{l}\text { Testemunha } \\
\text { Controle }(\%)^{(2)}\end{array}$ & $\frac{0,00 \pm 0,00}{-}$ & $\frac{1525,15 \pm 645,55 \mathrm{a}}{97,65}$ & $\frac{1103,13 \pm 637,56 \mathrm{a}}{98,66}$ & $\frac{0,00 \pm 0,00 \mathrm{c}}{-}$ & $\begin{array}{c}211,98 \pm 280,87 \mathrm{~b} \\
100,00\end{array}$ & $\begin{array}{c}0,00 \pm 0,00 \mathrm{~b} \\
-\end{array}$ & $\frac{0,00 \pm 0,00 \mathrm{a}}{-}$ \\
\hline
\end{tabular}

${ }^{(1)}$ Médias seguidas por pelo menos uma letra em comum, na coluna, não diferem entre si pelo teste Tukey (P>0,05); médias acompanhadas pelos respectivos erros-padrões. ${ }^{(2)}$ Calculado segundo fórmula de Abbott (1925). 
Tabela 3. Ação de Metarhizium anisopliae aplicado em pastagens de Brachiaria brizantha e Tifton 85, antes e após a infestação com fêmeas ingurgitadas de Boophilus microplus e após emergência das primeiras larvas ${ }^{(1)}$.

\begin{tabular}{|c|c|c|c|c|c|c|c|}
\hline \multirow[t]{2}{*}{ Tratamento } & \multicolumn{7}{|c|}{ Dias pós-infestação } \\
\hline & 0 & 35 & 38 & 41 & 48 & 55 & 61 \\
\hline Pré-infestação & $0,00 \pm 0,00$ & $707,90 \pm 668,14 a$ & $566,90 \pm 430,15 \mathrm{a}$ & $\begin{array}{l}\text { B. brizantha } \\
532,10 \pm 541,75 \mathrm{a}\end{array}$ & $380,00 \pm 654,81 \mathrm{a}$ & $17,20 \pm 54,39 \mathrm{ab}$ & $15,70 \pm 37,45 a$ \\
\hline Pós-infestação & $0,00 \pm 0,00$ & $612,80 \pm 592,24 \mathrm{a}$ & $578,10 \pm 855,08 \mathrm{abc}$ & $678,30 \pm 839,59 a$ & $193,40 \pm 302,89 \mathrm{ab}$ & $51,20 \pm 75,95 a$ & $8,40 \pm 26,56 a$ \\
\hline Pós-eclosão larval & $0,00 \pm 0,00$ & $1853,1 \pm 2395,64 \mathrm{a}$ & $558,80 \pm 551,66 \mathrm{ab}$ & $46,90 \pm 112,65 b$ & $32,70 \pm 51,24 \mathrm{~b}$ & $0,00 \pm 0,00 \mathrm{~b}$ & $0,00 \pm 0,00 \mathrm{a}$ \\
\hline Pré-infestação & $0,00 \pm 0,00$ & $716,60 \pm 931,76 b$ & $372,80 \pm 516,56 \mathrm{bc}$ & $\begin{array}{l}\text { Tifton } 85 \\
0,00 \pm 0,00 \mathrm{~b}\end{array}$ & $20,00 \pm 38,55 b$ & $0,00 \pm 0,00 \mathrm{~b}$ & $0,00 \pm 0,00 \mathrm{a}$ \\
\hline Pós-infestação & $0,00 \pm 0,00$ & $442,90 \pm 529,00 \mathrm{~b}$ & $247,40 \pm 362,53 \mathrm{c}$ & $0,00 \pm 0,00 \mathrm{~b}$ & $134,80 \pm 344,01 \mathrm{ab}$ & $0,00 \pm 0,00 \mathrm{~b}$ & $0,00 \pm 0,00 \mathrm{a}$ \\
\hline Pós-eclosão larval & $0,00 \pm 0,00$ & $488,00 \pm 584,02 \mathrm{~b}$ & $703,20 \pm 848,29 \mathrm{abc}$ & $0,00 \pm 0,00 \mathrm{~b}$ & $0,00 \pm 0,00 \mathrm{~b}$ & $0,00 \pm 0,00 \mathrm{~b}$ & $0,00 \pm 0,00 \mathrm{a}$ \\
\hline
\end{tabular}

(1)Médias seguidas por pelo menos uma letra em comum, na coluna, não diferem entre si pelo teste de Tukey (P>0,05); médias acompanhadas pelos respectivas erros-padrões.

tenha forte interação com as forragens utilizadas. Entretanto, quando se analisam as diferentes situações de pulverização dentro de cada capim, verifica-se que houve efeito apenas nas coletas realizadas entre o $41^{\circ}$ e 55ํ dia após infestação em $B$. brizantha, alcançandose melhores resultados no tratamento com aplicação do fungo logo após a emergência das primeiras larvas. Contudo, a maior recuperação de larvas ocorreu no 35ํㅜ e 380 dia pós-infestação em ambas as forragens, apesar destes achados não serem diferentes entre as situações de pulverização.

Comparando-se os resultados nos dois capins, verifica-se redução acentuada na quantidade de larvas recuperadas do 350 ao $41^{\circ}$ dia pós-infestação, principalmente no Tifton 85; a ação patogênica do fungo contribuiu decisivamente para que isso ocorresse.

Os resultados deste estudo demonstraram que M. anisopliae controla com eficácia a população de larvas de B. microplus nas pastagens, apresentando excelente potencial para o controle deste ácaro em condições de campo. Outras pesquisas devem ser realizadas com o objetivo específico de avaliar as variáveis que determinam o controle exercido por M. anisopliae sobre o carrapato B. microplus no campo.

\section{Conclusões}

1. Metarhizium anisopliae controla a população de larvas de Boophilus microplus em pastagens de Brachiaria brizantha e Tifton 85 artificialmente infestadas.

2. A eficiência do controle com o fungo é maior na pastagem de Tifton 85 do que na de B. brizantha.

3. A aplicação do fungo antes ou após a infestação da pastagem com fêmeas ingurgitadas, ou após a eclosão das larvas, tem efeito na ação do patógeno.

\section{Agradecimentos}

Ao Dr. Ricardo de Andrade Reis, do Dep. de Zootecnia da FCAV/Unesp, pela cessão da área de pastagens; à Capes, pela concessão da bolsa de mestrado à primeira autora; à Biocontrol Sistema de Controle Biológico, pela produção massal do fungo; à Fazenda Santa Joana, por ceder os animais para coleta das fêmeas ingurgitadas do carrapato.

\section{Referências}

ABBOTT, W.S. A method of computing the effectiveness of an insecticide. Journal of Economic Entomology, v.18, p.265-267, 1925.

ALVES, S.B.; PEREIRA, R.M. Produção de fungos entomopatogênicos. In: ALVES, S.B. (Ed.). Controle microbiano de insetos. 2.ed. Piracicaba: Fealq, 1998. p.853-857.

BITTENCOURT, V.R.E.P. Ação do fungo Metarhizium anisopliae sobre a fase não parasitária do ciclo biológico de Boophilus microplus. Revista da Universidade Rural, Série Ciências da Vida, v.16, p.49-55, 1994.

BITTENCOURT, V.R.E.P.; BAHIENSE, T.C.; FERNANDES, E.K.K.; SOUZA. E.J. Avaliação da ação in vivo de Metarhizium anisopliae (Metschnikoff, 1879) Sorokin, 1883 aplicado sobre Brachiaria decumbens infestada com larvas de Boophilus microplus (Canestrini, 1887) (Acari: Ixodidae). Revista Brasileira de Parasitologia Veterinária, v.12, p.38-42, 2003.

BITTENCOURT, V.R.E.P.; LIMA, A.P.; MASSARD, C.L. Uso do Metarhizium anisopliae (Metschnikoff, 1879) Sorokin, 1883, no controle do carrapato Boophilus microplus (Canestrini, 1887). Arquivos da Universidade Federal Rural do Rio de Janeiro, v.15, p.197-202, 1992.

CASTRO, A.B.A.; BITTENCOURT, V.R.E.P.; DAEMON, E.; VIEGAS, E.C. Efeito do fungo Metarhizium anisopliae (Metschnikoff, 1879) Sorokin, 1883 aplicado sobre Brachiaria decumbens infestadas com larvas não alimentadas de Boophilus microplus (Canestrini, 1887) (Acari: Ixodidae). Revista da Universidade Rural, Série Ciências da Vida, v.21, p.95-102, 1999. 
CASTRO, A.B.A.; BITTENCOURT, V.R.E.P; DAEMON, E.; VIEGAS, E.C. Eficácia do fungo Metarhizium anisopliae sobre o carrapato Boophilus microplus em teste de estábulo. Revista da Universidade Rural, Série Ciências da Vida, v.19, p.73-82, 1997.

CORDOVÉS, C.O. Carrapato: controle ou erradicação. 2.ed. Guaíba: Agropecuária, 1997. 130p.

CORREIA, A.C.B.; MONTEIRO, A.C.; FIORIN, A.C.; VERÍSSIMO, J.C. Effects of Metarhizium anisopliae on the Boophilus microplus (Acari: Ixodidae) in stabled cattle. Journal of Invertebrate Pathology, v.71, p.189-191, 1998.

EMBRAPA. Carrapato-de-boi. Disponível em: <www.cnpgc.embrapa.br/publicações/divulga/GCD42.html>. Acesso em: abr. 2004.

FRAZZON, A.P.G.; VAZ, I.S.; MASUDA, A.; VAINSTEIN, M.H. In vitro assessment of Metarhizium anisopliae isolates to control the cattle tick Boophilus microplus. Veterinary Parasitology, v.94, p.117-125, 2000.
GAUSS, C.L.B.; FURLONG, J. Comportamento de larvas infestantes de Boophilus microplus em pastagem de Brachiaria decumbens. Ciência Rural, v.32, p.467-472, 2002.

KAAYA, G.P.; HASSAN, S. Entomogenous fungi as promising biopesticides for tick control. Experimental and Applied Acarology, v.24, p.913-926, 2000.

MONTEIRO, A.C.; FIORIN, A.C.; CORREIA, A.C.B. Pathogenicity of isolates of Metarhizium anisopliae (Mestsch.) Sorokin towards the cattle tick Boophilus microplus (Can.) (Acari: Ixodidae) under laboratory conditions. Revista de Microbiologia, v.29, p.109-112, 1998.

SAUERESSIG, T.M. Estudo da fase não parasitária do carrapato de bovinos em pastagens cultivadas e nativa no Distrito Federal. Planaltina: Embrapa Cerrados, 1994. 15p. (Boletim de Pesquisa, 37).

VERÍSSIMO, J.C.; MACHADO, S.G. Fase de vida livre do ciclo evolutivo do carrapato Boophilus microplus. Zootecnia, v.33, p.4153, 1995.

Recebido em 1o de junho de 2004 e aprovado em 14 de dezembro de 2004 